\title{
Measuring support for tobacco control policy in selected areas of six countries
}

Robert G Laforge, Wayne F Velicer, Deborah A Levesque, Joseph L Fava, David J Hill, Penelope E Schofield, Dennis Fan, Hein De Vries, William O Shisana, Mark Conner

Cancer Prevention Research Center, University of Rhode Island, Kingston, Rhode Island, USA R G Laforge W F Velicer

D A Levesque J L Fava

Centre for Behavioural Research in Cancer Anti-Cancer Council of Victoria, Victoria, Australia

D J Hill

P E Schofield

Faculty of Business Administration, Chinese University of Hong Kong, Hong Kong, China

D Fan

Department of Health Education, University of Limburg, Limberg, Netherlands

H De Vries

University of the Western Cape, Cape

Town, South Africa

W O Shisana

Department of Psychology, University of Leeds, Leeds, UK M Conner

Correspondence to: Dr RG Laforge, Cancer Prevention Research Center, 2 Chafee Road, University of Rhode Island, Kingston, Rhode Island 02881-0808, RSA.

wa101@uriacc.uri.edu

\begin{abstract}
Objective-To explore the validity, reliability, and applicability of using a short, psychometrically sound survey instrument to measure population attitudes toward tobacco control policies.

Design-Surveys.

Subjects and setting-Student respondents attending university in Australia ( $n=$ 403), Hong Kong $(n=336)$, the Netherlands ( $n=351)$, South Africa $(n=$ $291)$, the United Kingdom $(n=164)$ and the United States $(n=241)$; total $n=1786$. Main outcome measure-The Smoking Policy Inventory (SPI), a 35-item scale. SPI scores were adjusted for age, income, gender, and smoking status. Estimates of internal consistency and tests of factorial invariance were conducted in each sample.
\end{abstract}

Results-Across all six countries, the SPI was found to be highly reliable and to have a consistent factor structure, indicating that the SPI scale represents a higher order construct that assesses general attitudes about tobacco control policy with five dimensions. In general, the degree of endorsement of anti-tobacco policies as measured by the SPI reflected the extent and strength of tobacco control legislation in those countries. Dutch students were the least likely, and Australian and Hong Kong students the most likely, to support tobacco control policies.

Conclusions-It is possible to develop appropriate and meaningful measurement tools for assessing support of tobacco control policies. Strong evidence was found for internal reliability and structural invariance of the SPI. The SPI may be a useful mechanism for monitoring ongoing policy initiatives, making cross-cultural comparisons, and evaluating population receptiveness to proposed policy approaches.

(Tobacco Control 1998;7:241-246)

Keywords: policies, tobacco control, Smoking Policy Inventory

\section{Introduction}

Although smoking rates are stable or declining in industrialised countries, they are on the increase in many developing countries. This has led health researchers to predict a worldwide pandemic of tobacco-related illness and death beginning early in the next century. ${ }^{1-4}$ An estimated 500 million people alive today will die from tobacco-related disease and death. ${ }^{2}$ These concerns have given rise to global strategies to implement comprehensive tobacco control policies. ${ }^{5-8}$

There is growing evidence from around the world that anti-smoking policies can result in decreases in tobacco consumption. ${ }^{9-13}$ Since 1970, the World Health Organisation has endorsed successively stronger resolutions appealing to governments to adopt comprehensive tobacco control legislation, arguing by implication that it is their ethical duty to protect the health of their people..$^{5-7}{ }^{14-16}$ Countries are urged to adopt polices that protect non-smokers' rights to breathe clean air; ensure that all health personnel set a non-smoking example; restrict production, promotion, and use of tobacco; eliminate sales and marketing to minors; require prominent health warnings; establish programmes to assist smokers to stop smoking; provide resources for promoting anti-smoking messages; and monitor trends in tobacco consumption. ${ }^{8}{ }^{17}$ As new policies are adopted it becomes increasingly important to evaluate the impact of these policies on smoking behaviours and on the public acceptance of tobacco control policies. This paper addresses one aspect of this problem: the need for sound measurement instruments that can reliably assess the support for tobacco control policies in different countries.

The purpose of this paper is to explore whether the Smoking Policy Inventory (SPI), a short instrument that measures degree of support for tobacco control policies, is internally consistent and a valid instrument across different populations. Details about the SPI instrument development and its initial validation have been published previously. ${ }^{18}$ Administration of the SPI in six different countries provides the opportunity to explore whether the measurement properties of the instrument can be replicated in different settings with varying traditions and degrees of historical support for tobacco control policies.

\section{Methods}

PROCEDURES

Public health researchers from six countries (Australia, Hong Kong, the Netherlands, South Africa, the United Kingdom, and the United States) were invited to participate in an international collaborative study of smoking policies. To facilitate comparability of the policy instrument and survey questionnaire, eligibility was restricted to researchers from 
countries whose primary language was English. The Netherlands was also included because, although English is a secondary language, the university student population is proficient in the language. Each research group was asked to administer the survey questionnaire to approximately 200-300 university students during the 1993 academic year. The sample size requirement was established as sufficient to enable assessment of the factor structure of the instrument in each setting.

A standardised survey questionnaire was developed at the University of Rhode Island (URI) and was printed on optical scan forms and mailed to the participating sites. All surveys were anonymous, and contained a code for identification of country of origin. Completed questionnaires were mailed back to URI for data processing and statistical analysis.

MEASURES

The questionnaire contained 28 items relating to demographics, smoking history, and knowledge about the risks associated with smoking. The 35-item Smoking Policy Inventory (SPI), a five-dimensional scale measuring attitudes and opinions about tobacco control and smoking policies was included. ${ }^{18}$ The five dimensions are: (a) advertising and promotion, (b) public education, (c) laws and penalties, (d) taxes and fees, and (e) environmental restrictions on smoking. Each of the five SPI scales have seven items which are scored from 1 to 5. The SPI has a hierarchical structure, producing scores for each of the five separate dimensions, and a total score indicating overall support of tobacco control policy. ${ }^{18}$

TOBACCO CONTROL POLICY ENVIRONMENT

All participating co-authors contributed a review of the tobacco control policy environment in their respective countries covering each of the five domains of the SPI at the time of the survey. With the exception of the United States, the reviews of the policy environment from each country were written before results of the surveys were available to the collaborators from that country. Because the American research team led this project, a sample review of the American policy environment derived from published sources was written and distributed to collaborators in the other countries as a model to be used for their review. These qualitative reviews are summarised and presented as background material for comparison with the results of SPI data from the corresponding student surveys. This qualitative summary was validated against published references relating to international tobacco control legislation. ${ }^{15}$

SAMPLE

Data were collected from a total of 1786 students from six countries: Australia ( $\mathrm{n}=$ 403), Hong Kong $(\mathrm{n}=336)$, the Netherlands $(\mathrm{n}=351)$, South Africa $(\mathrm{n}=291)$, the United Kingdom ( $\mathrm{n}=164)$, and the United States $(n=241)$. Researchers in each country chose the method for data collection, as explained below. In four countries the survey was administered in the classroom, in two (the Netherlands and the United Kingdom) the survey was delivered by mail or after class and returned later. Participation rates were not typically measured, although participation from countries that administered the survey in classrooms experienced few, if any, refusals. All data were collected during the 1993 academic year.

In Australia, the questionnaire was administered to 412 first-year university students from four universities in or near Melbourne, Australia. All students answered the questionnaire in classrooms or tutorial settings under the supervision of a tutor or research assistant.

In Hong Kong, questionnaires were handed out and completed in classrooms. A total of 336 students from six different courses participated. All students were ethnic Chinese and it is estimated that more than $95 \%$ of them had been living in Hong Kong for at least 10 years.

In the Netherlands, 900 questionnaires were distributed to the mail boxes of health science students of the University of Limburg. The purpose of the study was explained in an introductory letter, and those who returned the questionnaires (351 students, or $39 \%$ ) were eligible for one of seven prizes of 75 guilders (approximately US\$42).

In South Africa, the sample consisted of 291 undergraduate students enrolled in an industrial psychology course at the University of the Western Cape. The questionnaires were administered during class time and no special credit was given for participation. All students were black-that is, African, coloureds (approximately $60 \%$ ), or Indians. There were no refusals.

In the United Kingdom, the survey was administered to first-year psychology students at the University of Leeds, England. Questionnaires were handed out in a lecture class with the request that they be completed during the students' own time and returned to a collection point in the Department of Psychology. A total of 300 questionnaires were distributed and 170 questionnaires were returned, of which 163 responses were usable ( $54 \%$ response rate).

In the United States, 241 undergraduate students enrolled in an introductory psychology course at the University of Rhode Island completed the survey in the classroom under supervision of the instructor. Students were given course credit for their participation, and there were no refusals.

\section{Results}

SAMPLE CHARACTERISTICS

Selected characteristics of the student samples by country are presented in table 1 . The distribution of smoking status by country was about $20 \%$, except for Hong Kong, where only 3.0\% reported smoking. The distribution of former smokers was about $12 \%$, again with the exception of Hong Kong. The country samples differed by age, although the range of ages did not vary greatly. Students from South Africa, the United Kingdom, and the Netherlands tended to be older. The students were 
Table 1 Selected characteristics (\%) of the study samples across six countries

\begin{tabular}{|c|c|c|c|c|c|c|}
\hline & $\begin{array}{l}\text { Australia } \\
(n=403)\end{array}$ & $\begin{array}{l}\text { Hong Kong } \\
(n=336)\end{array}$ & $\begin{array}{l}\text { Netherlands } \\
(n=351)\end{array}$ & $\begin{array}{l}\text { South Africa } \\
(n=291)\end{array}$ & $\begin{array}{l}\text { United Kingdom } \\
(n=164)\end{array}$ & $\begin{array}{l}\text { United States } \\
(n=241)\end{array}$ \\
\hline Current smoker & 20.4 & 3.0 & 14.8 & 19.6 & 22.8 & 21.3 \\
\hline Former smoker & 12.7 & 3.0 & 11.3 & 8.2 & 17.3 & 11.1 \\
\hline \multicolumn{7}{|l|}{ Age (years) } \\
\hline$\leqslant 18$ & 38.3 & 16.7 & 14.0 & 8.7 & 20.9 & 24.9 \\
\hline $19-20$ & 42.0 & 62.2 & 34.8 & 22.9 & 38.7 & 62.2 \\
\hline $21-22$ & 8.8 & 19.0 & 23.9 & 18.8 & 11.0 & 10.0 \\
\hline $23-29$ & 7.3 & 1.8 & 24.8 & 38.5 & 10.4 & 2.9 \\
\hline$\geqslant 30$ & 3.8 & 0.3 & 2.6 & 11.1 & 19.0 & 0.0 \\
\hline Men` & 22.7 & 40.0 & 19.7 & 47.9 & 24.5 & 38.6 \\
\hline \multicolumn{7}{|l|}{ Family income ${ }^{\star}$} \\
\hline Lower & 2.8 & 11.0 & 1.7 & 27.0 & 5.5 & 2.5 \\
\hline Lower-middle & 15.0 & 38.2 & 4.6 & 22.5 & 12.3 & 11.3 \\
\hline Middle & 46.6 & 40.0 & 33.7 & 35.1 & 49.1 & 40.0 \\
\hline Upper-middle & 30.1 & 10.4 & 50.7 & 13.7 & 27.0 & 42.2 \\
\hline Upper & 5.5 & 0.3 & 9.2 & 1.8 & 6.1 & 4.2 \\
\hline \multicolumn{7}{|l|}{ Parent(s) smoked $\star$} \\
\hline$\%$ Yes & 51.1 & 47.6 & 63.0 & 49.0 & 46.0 & 57.3 \\
\hline \multicolumn{7}{|c|}{ No of friends who smoke* } \\
\hline 0 & 11.7 & 26.2 & 12.0 & 9.3 & 6.1 & 6.7 \\
\hline $1-2$ & 26.9 & 47.3 & 33.3 & 22.8 & 29.4 & 30.8 \\
\hline $3-4$ & 22.4 & 16.1 & 23.9 & 16.2 & 18.4 & 19.2 \\
\hline $5-6$ & 15.9 & 4.5 & 13.7 & 8.3 & 14.7 & 15.8 \\
\hline$\geqslant 7$ & 23.1 & 6.0 & 17.1 & 43.4 & 31.3 & 27.5 \\
\hline
\end{tabular}

${ }^{\star} \mathrm{p}<0.001$.

predominantly women, ranging from slightly more than $50 \%$ to almost $80 \%$. Family income varied considerably across countries as well, with South African students reporting lower family income rankings than the other countries. Students from the Netherlands and the United States were more likely to report that one or both of their parents were smokers. The number of friends who smoked varied across countries, and is generally consistent with other measures of smoking status.

PSYCHOMETRIC CHARACTERISTICS OF THE SPI An analysis using LISREL $^{19}$ examined the factorial invariance of the SPI across the six international samples. The hierarchical model previously fit to this measure, consisting of a single second-order factor (general attitude about smoking policy) and five first-order factors (the five domains measured by the SPI scales), was fit in each of the six samples. The Tucker-Lewis Index ${ }^{20}$ indicated a high degree of factorial invariance across the six samples.
The obtained values of the Tucker-Lewis Index for goodness of fit were: (a) Australia, 0.949; (b) Hong Kong, 0.909; (c) the Netherlands, 0.975; (d) South Africa, 0.918; (e) United Kingdom, 0.926; and (f) United States, 0.936.

Inter-item reliability of the SPI subscales was compared across countries using Cronbach's coefficient $\alpha$ and is presented in table 2. The SPI scales were internally consistent across samples from different countries. The item-scale reliability coefficient $\alpha$ for four of the five scales was 0.80 or greater-typically over 0.90-across samples from all six countries. The public education scale $\alpha$ ranged from 0.68 to 0.75 across countries.

\section{SMOKING POLICY INVENTORY}

The unadjusted mean SPI scale scores and standard deviations for each of the five SPI scales are also presented in table 2. The SPI scale scores represent the degree of support for tobacco control policy, with higher scores

Table 2 Means, standard deviations (SD), and coefficient a for the five Smoking Policy Inventory (SPI) scales for six countries

\begin{tabular}{|c|c|c|c|c|c|c|}
\hline SPI scale & $\begin{array}{l}\text { Australia } \\
(n=403)\end{array}$ & $\begin{array}{l}\text { Hong Kong } \\
(n=336)\end{array}$ & $\begin{array}{l}\text { Netherlands } \\
(n=351)\end{array}$ & $\begin{array}{l}\text { South Africa } \\
(n=291)\end{array}$ & $\begin{array}{l}\text { United Kingdom } \\
(n=164)\end{array}$ & $\begin{array}{l}\text { United States } \\
(n=241)\end{array}$ \\
\hline \multicolumn{7}{|c|}{ Advertising and promotion } \\
\hline $\mathrm{X}_{\mathrm{c}}$ & 25.0 & 22.8 & 22.6 & 24.2 & 24.4 & 21.4 \\
\hline SD & 7.07 & 6.01 & 7.51 & 7.94 & 7.51 & 7.55 \\
\hline$\alpha$ & 0.90 & 0.87 & 0.92 & 0.89 & 0.93 & 0.92 \\
\hline \multicolumn{7}{|c|}{ Public education } \\
\hline $\mathrm{X}_{\mathrm{c}}$ & 31.0 & 32.1 & 29.5 & 30.6 & 30.2 & 30.7 \\
\hline SD & 3.81 & 3.15 & 3.97 & 4.61 & 4.11 & 3.95 \\
\hline$\alpha$ & 0.68 & 0.77 & 0.70 & 0.73 & 0.75 & 0.75 \\
\hline \multicolumn{7}{|c|}{ Laws and penalties } \\
\hline $\mathrm{X}_{\mathrm{c}}$ & 27.6 & 27.0 & 19.9 & 24.7 & 28.2 & 24.2 \\
\hline SD & 5.83 & 5.20 & 7.17 & 7.28 & 5.14 & 7.18 \\
\hline$\alpha$ & 0.82 & 0.83 & 0.89 & 0.84 & 0.80 & 0.90 \\
\hline \multicolumn{7}{|c|}{ Taxes and fees } \\
\hline $\mathrm{X}_{\mathrm{c}}$ & 26.4 & 27.0 & 27.0 & 26.3 & 25.7 & 24.9 \\
\hline SD & 7.27 & 5.68 & 6.54 & 7.69 & 7.71 & 7.82 \\
\hline$\alpha$ & 0.92 & 0.89 & 0.90 & 0.90 & 0.94 & 0.94 \\
\hline \multicolumn{7}{|c|}{ Restrictions on smoking } \\
\hline $\mathrm{X}_{\mathrm{c}}$ & 27.7 & 29.9 & 26.1 & 27.0 & 24.8 & 26.5 \\
\hline SD & 6.60 & 4.90 & 7.64 & 6.92 & 7.44 & 8.02 \\
\hline$\alpha$ & 0.86 & 0.81 & 0.91 & 0.83 & 0.90 & 0.93 \\
\hline \multicolumn{7}{|c|}{ Total SPI score } \\
\hline $\mathrm{X}_{\mathrm{c}}$ & 137.7 & 138.8 & 125.1 & 132.8 & 133.0 & 127.7 \\
\hline SD & 23.8 & 18.0 & 24.4 & 29.0 & 26.0 & 29.1 \\
\hline
\end{tabular}

$\mathrm{X}_{\mathrm{c}}=$ unadjusted mean score. 
Table 3 Selected tobacco control policies by country sample in 1993, according to investigators' qualitative reports

\begin{tabular}{|c|c|c|c|c|c|c|}
\hline SPI scale & Australia & $\begin{array}{l}\text { Hong } \\
\text { Kong }\end{array}$ & Netherlands & $\begin{array}{l}\text { South } \\
\text { Africa }\end{array}$ & $\begin{array}{l}\text { United } \\
\text { Kingdom }\end{array}$ & $\begin{array}{l}\text { United } \\
\text { States }\end{array}$ \\
\hline \multicolumn{7}{|l|}{ Advertising and promotion } \\
\hline Ban tobacco ads in electronic broadcast media & Yes & Yes & Yes & Partial & Yes & Yes \\
\hline Ban tobacco ads in print media & Yes & No & Partial & No & No & Partial \\
\hline Ban billboard ads & Yes & Partial & No & No & No & No \\
\hline Ban free samples and promotional items & Yes & Yes & No & No & No & Partial \\
\hline Ban tobacco sponsorship of sports events & Yes & Partial & No & No & No & No \\
\hline Ban smokeless tobacco & Yes & No & No & No & No & Partial \\
\hline Ban tobacco promotion in public cinema & Yes & Yes & No & No & No & Partial \\
\hline \multicolumn{7}{|l|}{ Public education } \\
\hline Health warnings on cigarettes packs & Yes & Yes & Yes & Yes & Yes & Yes \\
\hline Health warnings on advertising & Yes & Yes & Yes & No & Yes & Yes \\
\hline Strong anti-tobacco health promotion & Yes & Yes & Partial & No & Partial & Yes \\
\hline \multicolumn{7}{|l|}{ Laws and penalties } \\
\hline Minimum age-of-purchase laws & Yes & Yes & No & No & Partial & Yes \\
\hline Strong enforcement of penalties for sales to minors & Yes & Yes & No & No & No & Partial \\
\hline Limits on pack size, including number of cigarettes per pack & Yes & No & Yes & No & No & Yes \\
\hline \multicolumn{7}{|l|}{ Taxes and fees } \\
\hline Federal excise tax on tobacco & Yes & Yes & Yes & Yes & Yes & Yes \\
\hline Tax increases intended to decrease smoking & Yes & Yes & Partial & No & Yes & Partial \\
\hline \multicolumn{7}{|l|}{ Environmental restrictions } \\
\hline Restaurants & Partial & Yes & Partial & No & Partial & Partial \\
\hline Hospitals and medical care facilities & Yes & Yes & Partial & Partial & Partial & Partial \\
\hline Public transportation & Yes & Yes & Partial & Partial & Partial & Yes \\
\hline Workplaces & Yes & Partial & Partial & No & Partial & Partial \\
\hline Schools & Yes & Yes & Partial & No & Yes & Yes \\
\hline
\end{tabular}

Yes = legislation or regulation is fully in effect.

$\mathrm{No}=$ legislation or regulation is not in effect.

Partial $=$ policy only partially implemented throughout country.

SPI $=$ Smoking Policy Inventory

indicating greater support. In general within each country, students were more likely to endorse policies to enhance public education on the health and social consequences of smoking, and increased environmental restrictions. Support tended to be lowest for advertising and promotional controls, as well as for laws and penalties.

Smokers in each of the six samples reported significantly lower scores on the SPI $(\mathrm{p}<0.01)$, suggesting less favourable attitudes toward tobacco control polices than among nonsmokers. The correlation between total SPI score and current smoking status ranged from $r=-0.36$ to $r=-0.48$ across the six samples. Similarly, total SPI score was negatively associated with number of friends who smoke in each of the six samples (range: $r=-0.16$ to $r=$ $-0.37, \mathrm{p}<0.01)$. Men scored significantly lower than women on total SPI score in three samples: South Africa $(r=-0.19)$, Hong Kong $(r=-0.21)$, and the United Kingdom ( $r=$ -0.28). There was a weak but statistically significant association with family income in the Netherlands $(r=-0.18)$ and Hong Kong $(r=-0.16)$ samples.

\section{TOBACCO CONTROL POLICY}

A comprehensive review of the details of tobacco control policy in each of the six countries is beyond the scope of this paper. Characterising the policy environment requires an evaluation of the mix of local, regional, or national governmental legislation, as well as public agency activities and private industry initiatives. ${ }^{17}$ A qualitative overview of the policy environment can provide insight into the historical background, useful for evaluating the external validity of the results obtained from the student surveys. Table 3 summarises the investigators' qualitative reports of each country's policy environment using several tobacco control initiatives that were assessed during the study year. The policies were ranked by degree of adoption or implementation (full, partial, or none). Table 3 suggests that during the study year tobacco control policies were more likely to have been adopted or more fully implemented in Australia and Hong Kong, and were least likely to have been adopted in the Netherlands and South Africa. The United States and United Kingdom were between these extremes.

RELATIONSHIP OF SPI SCORES TO THE TOBACCO CONTROL POLICY ENVIRONMENT

Because the six student samples in this study were drawn for convenience, and are not representative of the general population-nor of the general population of students-within each country, observed differences among countries may misrepresent true differences among them. However, comparisons can be made within country, and with the general pattern of relationships between SPI scores and the policy environment. It is important to remember that assessment of the policy environment provides a snapshot of a dynamic process, which in this case reflects what was occurring in 1993. Significant changes have taken place in some countries, such as South Africa, since 1993, but it is beyond the scope of this article to discuss these changes.

In general, the SPI score appears to be related to the tobacco control policy environment in each country. For example, students from the two countries that have the most aggressive programmes of tobacco control, Australia and Hong Kong, were also very likely to endorse anti-smoking policies generally. Students from Australia exhibited strong support for advertising and promotion regulations, which is consistent with more than two decades of anti-smoking activism in that country, which has led to enactment of some of the most stringent advertising and promotional 
regulations in the world. Students from the Netherlands, which has fewer tobacco control policies, tended to score low on the SPI. Students from the United Kingdom and Australia exhibited relatively greater support, and Dutch students relatively less support, for strict laws and penalties for tobacco sales to minors than all countries.

\section{Discussion}

A major finding of this study is that meaningful and standardised assessment of tobacco control policy can be made using the Smoking Policy Inventory. The 35-item SPI provides a consistent measure of support for tobacco control policy, which was found to be robust across a variety of samples that were heterogeneous with respect to gender, type of student, income, smoking status, and parental and social smoking environment. Across all six countries, the psychometric analyses revealed excellent internal consistency and a highly comparable factor structure for the SPI. These findings provide strong evidence of the internal reliability and the structural invariance of the SPI, implying that the five underlying constructs of tobacco control policy are common across countries, and can be accurately measured and compared using the SPI scores. Although this study relied on nonrepresentative convenience samples, and is thereby limited in its utility for making comparative statements, the measurement properties of the SPI suggest that further research is indicated to evaluate its applicability as a practical instrument for cross-cultural research and policy evaluation. The SPI should be applied cross-culturally, using more comparable samples, to explore this possibility.

The observed correspondence between the tobacco control policy environment and SPI score is further evidence of the validity of the SPI. Public support for tobacco control policy as measured by the SPI reflects in some measure the historical and policy environment in each country. Countries with recent history of strong advocacy for tobacco control, such as Australia and Hong Kong, tended to score high. On the other hand, the Netherlands, which is third in Europe with respect to tobacco distribution, production and has a strong liberal tradition with regard to tobacco control issues, scored low. Dutch students were the most likely to endorse taxes and fees, which may relate to the generally favourable attitude by the Dutch toward using taxes as an acceptable policy mechanism for addressing many social problems.

Students from the three countries with more moderate tobacco control policy environments - the United States, the United Kingdom, and South Africa-expressed moderate levels of support for anti-smoking policies. At the time of the survey, South Africa was undergoing a major social transition away from the apartheid system toward a more egalitarian future. Although the tobacco control environment in South Africa might be characterised as relatively weak in 1993, the modest support for tobacco control exhibited by the mostly black and coloured students may represent growing aspirations for new policies in a government in the midst of major social change. The modest support for tobacco control policy in the United States and United Kingdom may reflect the mixed success that tobacco control advocates have had in achieving widespread adoption of effective tobacco control regulatory policies in those countries. Strong support for regulations against tobacco sales to minors was found in the United Kingdom, which at the time had relatively weak tobacco control policies in this area. If this finding is representative of the population at large, it would suggest that the political environment may be ripe for strategic advocacy of laws and penalties for sales to minors in the United Kingdom.

Similar to findings from other studies of support for smoking policy, ${ }^{21}{ }^{22}$ smoking status, gender, and income were found to be related to support for tobacco control policies. Separate analyses of data from the six countries have found that previous smoking experience is the most important predictor of SPI score. ${ }^{18} 2324$ Indeed, it is a consistent finding that smokers report less support for tobacco control policies than non-smokers. ${ }^{22}{ }^{25} 26$ This relationship held for current and former smoking status, parental smoking history, number of friends who smoke, and being bothered by smoke.

Additional research is needed to further develop the SPI. One limitation of the SPI relates to the observed ceiling effects in the SPI education subscale. Public education received strong endorsement in all countries, suggesting that the educational policies as measured by this subscale are widely accepted and not controversial. The high scores (average score 30.7 out of a possible 35) also imply that the education scale may be too restrictive due to ceiling effects, which place an upper limit on the variance that can be assessed by this scale. This finding indicates that the education subscale is of limited usefulness in assessing variation in support for tobacco control education. Another potential area for further research includes assessing support for litigation as a mechanism for tobacco control policy. This was not assessed in the initial development of the SPI, but has recently become an important focal point in discussions of tobacco policy in the United States.

The validity and applicability of the SPI have only been partially demonstrated in this study. Additional research with adult samples will be needed to demonstrate its validity in general population settings. Such studies should also assess populations longitudinally to evaluate the stability and variability of the SPI over time. The use of convenience samples, which may be prone to selection bias, is an important limitation of this study. There are important differences in sample selection across the six countries in this study, and comparison of differences from these data cannot be considered valid. The particular convenience samples described here are not representative samples of the general population, nor of the student 
population in these countries. For example, the smoking rate of $15 \%$ in this Dutch student sample was considerably lower than the national average of $35 \%$ for young people aged 18-24 years in 1993 (personal communication with Dr DeVries, 12 December 1994). Similarly, the smoking rate among Australian college students in this study $(20 \%)$ is lower than that reported for all Australian adults aged $20-24$ years $(36 \%){ }^{27}$ In the other four countries, however, the smoking rates in our samples are similar to those in age-comparable general population studies. ${ }^{28-31}$

\section{Conclusion}

This study addresses an important gap in the policy development literature, and demonstrates that it is possible to develop appropriate measurement tools for assessing support for tobacco control policies that can be broadly applicable. There are many potential applications of the SPI for tobacco control research, evaluation, and policy development. The short 35-item portable nature of the SPI makes it especially appropriate for large population survey research, and for monitoring within-population trends. The findings of this study imply that cross-cultural comparisons of tobacco control policy using the SPI may also be appropriate, given comparably representative samples. The SPI has been replicated across several diverse samples and has been shown to be highly reliable, structurally invariant, and with good external validity. The relatively short length of the instrument, capturing five broad dimensions of tobacco control policy, makes it a convenient substitute for the unstandardised approach to survey assessment of tobacco control policies.

This work was supported by Grants CA27821, CA63045, and CA50087 from the National Cancer Institute. The authors would like to thank Ruth Roemer for her thoughtful review of an earlier draft of this paper.

1 Peto R, Lopez AD, Boreham J, et al. Mortality from smoking in developed countries 1950-2000: indirect estimates from in developed countries 1950-2000: indirect estimates from national

2 Peto R, Lopez $\mathrm{AD}$. Worldwide mortality from current smoking patterns: WHO consultative group on statistical aspects of tobacco-related mortality. In: Durston B Jamrozik K, eds. Tobacco and health 1990 - the global war. Proceedings of the seventh world conference on tobacco and health, 1-5 April 1990. Perth: Health Department of Western Australia, 1990:66-8.

3 Peto R. Keynote address. 27th Annual meeting of the Society for Epidemiologic Research, Miami Florida, 16 June 1994

4 Marshal $M$. The second fatal impact: cigarette smoking, chronic disease and the epidemiological transition in Oceania. Soc Sci Med 1991;33:1327-1342.

5 World Health Organisation. Controlling the smoking epidemic: report of the WHO Expert Committee on Smoking Control. WHO technical report series no 636. Geneva: WHO, 1979.
6 World Health Organisation Smoking control strategies in developing countries: report of a WHO Expert Committee. WHO technical report series no 695. Geneva: WHO, 1983.

7 World Health Organisation. Legislative strategies for a smokefree Europe. Copenhagen: WHO European Office, 1987.

8 World Health Organisation. Action plan on tobacco or health for 1995-1999. Manila, Philippines: WHO Regional Office for the Western Pacific, 1995.

9 New Zealand Toxic Substances Board. Tobacco or health: an end tobacco advertising and promotion. Wellington, New Zealand, 1989.

10 Pierce JP, Macaskill P, Hill D. Long-term effectiveness of mass media led anti-smoking campaigns in Australia. Am $\mathcal{F}$ Public Health, 1990;80:565-9.

11 US Department of Health and Human Services. Smoking and health in the Americas: a 1992 report of the surgeon general in collabration with the Pan American Health Organization. Atlanta, Georgia: Centers for Disease Centre, Office on Smoking and Health, 1992 (DHHS Publication No (CDC) 92-8419)

12 American Medical Association Council on Scientific Affairs. The worldwide smoking epidemic: tobacco trade, use and control. $7 A M A$ 1990;263:3312-18.

13 Pierce JP, Evans N, Farkas AJ, et al. Tobacco use in California. An evaluation of the tobacco control program, 1989-1993. San Diego, California: University of California, 1994:41-59.

14 World Health Organisation. Legislative responses to tobacco use. Foreword by Ruth Roemer. Dordrecht, Netherlands: Martinus Nijhoff, 1991

15 Roemer R. Legislative action to combat the world tobacco epidemic, 2nd ed. Geneva: World Health Organisation, 1993.

16 Chapman S, Yach D, Salogee Y, et al. All Africa Conference on Tobacco Control. BMF 1994;308:189-91.

17 Roemer R. Fighting threats to legislative advances in tobacco control. Presented at the 122 nd annual meeting of tobacco control. Presented at the 122nd annual meeting of the American Public

18 Velicer WF, Laforge RG, Levesque DA, et al. The development and initial validation of the Smoking Policy Inventory. Tobacco Control 1994;3:347-55.

19 Joreskog KG, Sorbom D. LISREL 7: A guide to the program and applications, 2nd ed. Chicago, Illinois: SPSS, 1989.

20 Tucker LR, Lewis C. A reliability coefficient for maximum likelihood factor analysis. Psychometrika 1973;38:1-10.

21 Pederson LL, Shelley BB, Ashley MJ, et al. A population survey on legislative measures to restrict smoking in Antario: 2. Knowledge, attitudes

22 Jeffery RW, Forster JL, Schmid TL, et al. Community attitudes toward public policies to control alcohol, tobacco, and high fat food consumption. Am $\mathcal{F}$ Prev Med 1990;6:12-19.

23 Laforge RG, Velicer WF, Levesque DA, et al. Predictors of support for anti-smoking policies among students in six countries. Pres Society of Behavioral Medicine, 22-25 March 1995.

24 Schofield PE, Hill DJ, Velicer WF. Smoking policy interventions: is Australian youth in favor of them? Health Promotion $\mathcal{7}$ A ust 1996;7:4-10.

25 Pederson L, Bull SB, Ashley MJ, et al. A population survey on legislative measures to restrict smoking in Ontario: 3. Variables related to attitudes of smokers and nonsmokers. Am F Prev Med 1989;5:313-21.

26 Martin G, Steyn K, Yach D. Belief about smoking and health and attitudes toward tobacco control measures. South Afr Med F 1992;82:241-5.

27 Hill DJ, White VM. Australian adult smoking prevalence in 1992. Aust f Public Health 1995:19:3.

28 Hong Kong Council on Smoking and Health. Health or smoking: the facts 1990. Hong Kong, China: Council on Smoking and Health, 1990.

29 Slayen PW. What do young adults really know, think and do about their health? South Afr Med f 1980;57:877-80.

30 Borkon L, Baird DM, Siff M. Tobacco smoking among students at the University of Witwatersrand, Johannesburg. South Afr Med F 1983,64:809-12.

31 Johnston LD, O'Malley PM, Bachman JG. National survey results on drug use from the Monitoring the Future Study, 1975-1994, Wol. II. College students and young adults. RockNile, Maryland: National Institute on Drug Abuse, 96-4027.) 